\title{
Invasive Mechanical Ventilation in Premature Infants: Where do we Stand Today?
}

\section{Sergei Roumiantsev ${ }^{1,2}$}

1 Instructor in Pediatrics Harvard Medical School, USA

${ }^{2}$ Attending Physician, Massachusetts General Hospital for Children, Newborn Services, USA

\begin{abstract}
Respiratory support is an essential part of care during clinical course of premature infants. Despite the wide-spread use of non-invasive modes of ventilation today the most vulnerable extremely premature infants are still likely to require invasive mechanical ventilation. Multiple studies have been published addressing advantages and disadvantages of various modes of ventilation in neonates. In this review we critically evaluate data supporting use of different modalities of invasive mechanical ventilation in premature infants. Specific attention is paid to aspects of synchronized- and patient-triggered ventilation, comparison of volume-targeted, pressure-limited modes of ventilation and high frequency ventilation.
\end{abstract}

As a separate subject we assess the use of multiple techniques to shorten the length of invasive mechanical ventilation including modes of ventilation, post-extubation support, permissive hypercapnea and targeting lower oxygen saturation.

\section{Introduction}

On August 9, 1963 the entire world was shocked to learn that Patrick Bouvier Kennedy, newborn son of the beloved American president died at the age of 2 days. He was born in Otis Air Force Base Hospital at 34 weeks of gestation with birth weight of 4 pounds and 10.5 ounces. He was transported to Children's Hospital Boston with the diagnosis of hyaline membrane disease, now called neonatal Respiratory Distress Syndrome (RDS). As newspapers reported in his obituary very little treatment was available besides observation and blood chemistry. This event brought to public view and raised awareness of how little medical care is available for the smallest patients. It was a pivotal point to accelerate the development of dedicated specialized Neonatal Intensive Care Units (NICUs) across the country. Development of mechanical ventilation and other new therapies for neonates in general and premature babies in particular has resulted in dramatic improvements in survival of premature infants as well as the ability to rescue extremely premature infants at lower gestational than was imaginable in the 1960s. The last two decades were marked by improved survival of extremely premature infants $[1,2]$.

Infant mortality due to RDS in the United States has decreased dramatically from 268 in 100,000 live birth in 1971 [3] to 14.7 per 100,000 live births in 2008 [4]. While multiple factors contributed to this statistic, an understanding of pathophysiology of RDS and development of mechanical ventilation for infants was a key element of this success. One of the early studies showing a beneficial effect of mechanical ventilation on survival compared mechanical ventilation (negative pressure ventilation, pressure limited positive pressure and volume limited positive pressure ventilation) vs. no ventilation in premature infants with RDS was published in early 1970 [5]. This study was especially interesting historically, as 40 years later we continue to debate the efficacy of various ventilator strategies and non-invasive ventilator support.

Since the introduction of invasive mechanical ventilation of neonates we have been faced with complications of chronic lung disease in premature infants. Northway described the chronic pulmonary syndrome associated with intermittent positive-pressure ventilation and high oxygen concentration, Broncho Pulmonary Dysplasia(BPD) [6]. At the same time Gregory introduced Continuous Positive Pressure Ventilation (CPAP) as an alternative to invasive mechanical ventilation [7]. The 1970s and 1980s were marked by the development and use of neonatal Time Cycled Pressure Limited (TCPL) ventilators [8,9] and high frequency ventilators $[10,11]$. Despite the availability of more sophisticated neonatal ventilators, invasive mechanical ventilation remained the major risk factor for development of BPD. Centers that used less invasive ventilation had lower rates of Chronic Lung Disease (CLD) $[12,13]$. These studies have shifted the discussion and the interest in neonatal mechanical ventilation towards how we can use less of mechanical ventilation, with the hope of reducing BPD. Current approaches to CPAP and Noninvasive Positive Pressure Ventilation (NIPPV) is reviewed elsewhere in the current issue of the Journal. Although recent data suggest that the use of CPAP and NIPPV may be beneficial, a majority of the most vulnerable infants still require intubation and invasive mechanical ventilation. Several large studies such as SUPPORT [14] and COIN [15] trials show that over 50\% of infants with gestational age 24-28 weeks require intubation and mechanical ventilation during their hospital stay, even with careful selection of the patients enrolled into a CPAP arm. Smaller randomized trials show that NIPPV reduced the need for intubation and invasive mechanical ventilation, but exclude the most vulnerable infants less than 26 weeks of gestation $[16,17]$. The prevalence of moderate to severe BPD among infants less than 26 weeks remains $>60 \%$ [18]. The goal of this review is to discuss commonly used approaches in invasive mechanical ventilation of neonates and the benefits of novel modalities.

\section{Challenges of Neonatal Ventilation}

Mechanical ventilation of small neonates poses multiple technological challenges, resulting in substantial delays in the

\footnotetext{
*Corresponding author: Sergei Roumiantsev,Attending Physician, Massachusetts General Hospital for Children, Newborn Services,55 Fruit Street FND 526A, Boston, MA 02114, USA, Tel: 617-724-9040; Fax: 617-724-9346; E-mail: sroumiantsev@partners.org
}

Received December 12, 2012; Accepted February 28, 2013; Published March 04, 2013

Citation: Roumiantsev S (2013) Invasive Mechanical Ventilation in Premature Infants: Where do we Stand Today? J Pulmon Resp Med S13: 002. doi:10.4172/2161-105X.S13-002

Copyright: ( $) 2013$ Roumiantsev S. This is an open-access article distributed under the terms of the Creative Commons Attribution License, which permits unrestricted use, distribution, and reproduction in any medium, provided the original author and source are credited. 
translation of new strategies from the pediatric and adult world. The challenges resulting from the pathophysiology of the neonatal diseases and the small size of our patients include rapid Respiratory Rate (RR), low and/or rapidly changing lung compliance, highly compliant chest wall, very short inspiratory time (iT) and very small tidal volumes $(\mathrm{Vt})$.

Another layer of complexity is added by the air leak associated with use of uncuffed Endotracheal Tubes (ETTs) in neonates. This practice is based on the discouraging reports of tracheal injury and necrosis published on a small group of patients [19]. Although materials used today are vastly superior to the ones previously used, the practice continues. Recently published reports have demonstrated the safe use of cuffed ETTs in small children and neonates for anesthesia [20]. No studies are available assessing the use of cuffed tubes in premature infants over prolonged periods of mechanical ventilation. Advances in microprocessor driven ventilators now compensate for the obligatory air leak around uncuffed ETTs and allow accurate volume and flow measurements, essential for most ventilator modes. Combination of persistent air leak and small Vt, as small of 2-3 ml, makes flow detection and accurate measurement of inspiratory and expiratory Vt difficult. Introduction of additional flow and volume measuring equipment at the airway opening helps to partially alleviate these problems yet it comes at the expense of an increase in circuit dead space. Modern ventilators and the software accompanying them have become more complex and sophisticated with many these ventilators certified for use in neonatal, pediatric and adult patients. Available modes of ventilation have exponentially increased, with many ventilators offering mixed modes of ventilation. In the absence of convincing evidence demonstrating advantages of one mode of ventilation over another in neonates, clinical staff is left with a plethora of possible strategies.

Recent international surveys on the modes of ventilations in the NICU have demonstrated great variability $[21,22]$. Additional confusion is added by non-standard terminology used in different ventilators. Several attempts have been made to formalize the nomenclature of mechanical ventilation, but standardization has not been achieved $[23,24]$. An approach to the taxonomy of mechanical ventilation has been proposed by Keszler [25]

- How is breath initiated? (Patient or ventilator triggered)

- How is gas flow controlled during breath delivery? (Pressure or volume controlled)

- How is breath terminated? (Time, flow or volume cycled)

We will use this approach to characterize different modes of ventilation in this review.

\section{Synchronized and Patient Triggered Mechanical Ventilation}

Synchronization of mechanical ventilation in neonates followed its development in adult ventilators. Several studies demonstrated shortterm benefits of synchronized ventilation in neonates such as, improved oxygenation [26], reduced tidal volumes [27] and reduced blood pressure fluctuation [28]. Note that synchronized mechanical ventilation is not synonymous with patient triggered mechanical ventilation. Use of high Respiratory Rate (RR) with short Inspiratory Time (IT), dubbed High Frequency Positive Pressure Ventilation (HFPPV), results in excellent synchronization in small premature infants. Cochrane reviews analyzed multiple trials comparing synchronized vs. non-synchronized ventilation in neonates $[29,30]$ and concluded that synchronization reduced air leaks and reduced the duration of mechanical ventilation. There were no conclusive data in these studies supporting long-term benefits of synchronized ventilation or patient triggering versus HFPPV. Patient-triggered ventilation has become standard of care today. Several studies have demonstrated higher sensitivity and decreased asynchrony of flow-triggered ventilation with sensor placed at the end of a patient's airway, versus pressure triggering $[31,32]$. Flow-triggered ventilation is now the standard of care for premature neonates. The same flow sensors are also used to determine Vt, essential for volume controlled/ guarantied ventilation. A disadvantage of using a flow sensor at the Y-connector of endotracheal tube (proximal sensor) is an increase in dead space. The increase in dead space does not appear to affect ventilation in premature infants [33]. Newer ventilators offer highly sensitive flow and pressure sensors built in the ventilator circuit (distal sensor). While distal sensors underestimate delivered tidal volume [34], it is not clear if they have the same sensitivity as proximal sensors for patient triggering. Distal, built-in flow sensors were used in the initial clinical trials of patient triggered mechanical ventilation.

From a physiological perspective, flow or pressure triggering lags behind patient breath initiation. A new approach utilizes detection of Electrical activity of the Diaphragm (Edi) to trigger the mechanical breath. Neurally Adjusted Ventilatory Assist (NAVA) - triggering is based on measuring of Edi of a patient via placement of nasogastric tube containing electrodes below and above diaphragm. The initial reading is filtered, processed and amplified via complex algorithm to isolate specific Edi signal. Recent reviews have discussed mechanisms and development of NAVA technology for neonates and adults $[35,36]$. Studies using NAVA are small and address only short-term outcomes, but available date are encouraging. Alander et al. [37] showed NAVA synchronization was superior to pressure and flow triggering in infants with acute bronchiolitis. Clement et al. [38] demonstrated that NAVAtriggering reduced trigger delay, improved ventilator response times, and decreased work of breathing. Use of NAVA technology offers potential advantages beyond breath-triggering. Edi provides complete information about entire breathing cycle allowing NAVA to be used as a stand-alone assist mode of ventilation. Edi signal analysis can be used for initiation of breath, size of breath and termination of breath. Some initial studies that use NAVA in neonates are encouraging in terms of safety and very short-term impact [39-42]. Patients were ventilated from 20 minutes to 24 hours and the results were compared with data collected on a conventional ventilator prior to initiation of NAVA. NAVA was associated with better ventilator synchrony, decreased Peak Inspiratory Pressure (PIP) and oxygen requirement, with no adverse events. NAVA remains an experimental mode of invasive mechanical ventilation with many unanswered questions. The major concern is whether NAVA can be effective with the immature breathing center of extremely premature infants with rapidly changing lung compliance of hyaline membrane disease. NAVA is only available today on one ventilator: the SERVO-iMaquet ${ }^{\circledR}$ (Maquet Critical Care, Solna, Sweden).

\section{Pressure-Limited and Volume-Targeted Ventilation}

Pressure limited ventilation remains a very popular mode of ventilation due to its simplicity and extensive experience with it in NICUs [22,43]. Synchronized Intermittent Mandatory Ventilation (SIMV) and Assist Control (AC) are both TCPL modes of ventilation with set PIP and iT. They are very similar except that in SIMV, spontaneous breaths occurring faster than the set ventilator rate are not supported and in AC every patient breath is supported to a set PIP. Pressure Support Ventilation (PSV) supports every breath with set pressure, but terminates an inspiratory breath when inspiratory flow drops below a predefined threshold (e.g. inspiratory flow velocity declines to $80 \%$ of the peak inspiratory flow). Since the peak inspiratory flow generated by the patient is variable from breath to breath, in PSV 
iT varies accordingly. These three modes of pressure-limited ventilation are the commonly used and represent a progression from less to more control of mechanical ventilation by the patient. The presumed advantages of this progression include increased patient comfort, better synchrony, decreased pressures used for ventilation and decreased ventilator induced lung injury. Short term benefits from use of PSV over SIMV, include a decrease in mean airway pressure and peak inspiratory pressure [44] and improvement in respiratory rate and tidal volumes [45]. A recent Cochrane review [46] analyze available trials comparing PSV and time cycled ventilation. Only two randomized trials were eligible for analysis involving a total of 19 patients and addressing only short-term impact of PSV [47,48]. No trials addressed the impact of PSV on rate of BPD or other long-term outcomes. Thus, it is uncertain whether there is benefit to using PSV over SIMV.

One of the main problems with pressure-limited ventilation is a highly variable tidal volume, in the settings of rapidly changing lung compliance in premature infants. It is now established that excessive volume rather than pressure is the main cause of ventilator induced lung injury (VILI), even after a short period of mechanical ventilation [49-51]. At the same time hypoventilation and poor lung recruitment due to low Vt have been associated with adverse outcomes, in particular, increased rate of IVH [52,53]. With this recognition, control of Vt has become the most likely solution to reduce VILI. Although traditional volume-controlled ventilation has been available in adult and pediatric patients for many years, its adoption in the NICU has been slow. Classical volume-controlled ventilation measures the volume injected in the circuit and it is presumed to be the volume received by the patient. As discussed above our patient size and airleak around uncuffed endotracheal tubes, has made this approach challenging. Several solutions, using microprocessor technology, have been offered to solve this problem and currently several volume-targeted ventilators are available for use in neonates. These modes are different from true volume-controlled ventilation and an excellent review by Kezler [25] details the differences between these modes of ventilation. In brief, most of the volume-targeted modes of ventilation used in the NICU are indeed based on pressure-limited time cycled mode. That includes pressure-regulated volume controlled (PRVC), Volume-Controlled (VC) and Volume Guarantee (VG). Today these modes are most commonly used volume-targeted modes of ventilation in NICU. The primary difference between them is the algorithm used to target $\mathrm{Vt}$ and limit pressure per each breath. PRVC and VC are used in most of the trials targeted inspiratory Vt and VG targets expiratory Vt at the ' $\mathrm{Y}$ ' connector at the end of the ETT.

Multiple trials have been published over the last decade comparing various pressure-limited and volume-targeted ventilation strategies in neonates [54-58]. Recently published Cochrane review and metaanalysis $[59,60]$ have identified 13 trials comparing volume-targeted to pressure-limited ventilation. Nine of these trials with the data available for 630 patients have been included in systematic review and metaanalysis. Some of the outcome analysis has been limited to seven of these 13 trials with a total of 556 patients. These studies support the safety of volume-targeted ventilation in premature infants. Metaanalysis has also demonstrated significant reduction in combined rates of death and BPD and grades 3-4 Intra-Ventricular Hemorrhages (IVH) or Periventricular Leucomalacia (PVL). There was also a reduction in short-term complications such as hypocarbia, pneumothorax, and a possible reduction in the length of ventilation. There were borderline significant reductions in rate of BPD. One major problem remains, that none of these clinical trials have been designed nor powered to detect differences in long-term outcomes for these infants. While there are problems with the design of these trials, existing evidence outlined in the Cochrane review is sufficiently strong to suggest that volumetargeted ventilation should become a predominant mode of ventilation in neonates. Nonetheless, based on several surveys of ventilation practices in NICUs outside of the US, pressure-limited ventilation still dominates $[21,61]$.

\section{High-Frequency Ventilation}

The concept of High-Frequency Ventilation (HFV) was introduced in 1970s first in animal models [62] and then in adults [63]. It has become a very attractive mode of ventilation since it utilizes small tidal volumes and very rapid respiratory rates. Potential advantages include safer use of higher mean airway pressure, due to absence of conventional breaths and the ability to uncouple management of ventilation and oxygenation. First reports published in neonates in 1980s were promising $[64,65]$. In addition, experimental data suggested other possible benefits including reduced VILI, improved ventilation and oxygenation in the setting of acute lung injury and improved ventilation in the presence of airleak [66-68]. Although several ventilator designs are available, the most commonly used HFV in the USA includes High Frequency Oscillator Ventilator (HFOV) and High-Frequency Jet Ventilator (HFJV). Over the last two decades HFV has been used primarily for the following indications:

- Primary mode of ventilation for treatment of acute respiratory failure in term and near term infants.

- Primary mode of ventilation for extremely premature infant with respiratory distress syndrome.

- Rescue mode of ventilation for neonates in the setting of failing conventional ventilation.

Previously mentioned surveys [21,22] estimate the use of HFV between $11-15 \%$ in NICUs. It is reasonable to speculate that most of the units reported use of HFV as a primary mode of ventilation. Rescue mode of HFV ventilation might not be reflected in these surveys, making combined use of HFV higher.

Multiple trials have compared HFV with conventional ventilation. While some of studies demonstrated a reduction in the rate of BPD and length of mechanical ventilation [69-71], decreased oxygen use [72] or no significant changes in outcomes $[73,74]$, others have suggested increased risk of severe IVH and PVL [75] and increased air leak $[76,77]$. There have been multiple attempts to explain these differences including use of different type of ventilators, limited experience in using HFV in some centers and use of low lung volume recruitment strategy in the trials with worse outcomes. Several reviews and metaanalyses have been published summarizing the results of most of the trials. Cochrane review [78] has analyzed effect of elective HFOV versus conventional ventilation in premature infants that included 3652 patients from 17 trials and concluded that effect of HFV on CLD was inconsistent among the trials and not statistically significant. Adverse neurodevelopmental outcomes such as Grade 3-4 IVH and PVL have been limited to trials using low lung volume strategy, but in the metaanalysis this was not statistically significant. There was some reduction in the rate of retinopathy of prematurity. Overall authors have concluded that no significant advantage of HFOV over conventional ventilation has been demonstrated. Another meta-analysis reviewed individual patient data and included 3229 patients from 10 randomized controlled trials with some overlap with the Cochrane review [79]. There was no statistically significant difference in combined risk of death or BPD, death or severe neurological outcomes or all three combined. Subgroup analysis showed no specific benefit based on patient characteristic such 
as birth weight, gestational age, exposure to antenatal steroids and etc. As they evaluated secondary outcomes they have found that there is a small increase in any air leak, but decrease in ROP and decrease in treatment of PDA in HFOV group. Overall both reviews concluded that the data do not support advocating for one mode of ventilation in premature infants.

Another Cochrane review specifically evaluated the benefits of high frequency jet ventilation as a primary mode of ventilation in premature infants [80], reanalyzing the data in 2009 with the same result. Three trials were eligible for review and meta-analysis showed a slight reduction in the rate of $\mathrm{BPD}$ and no differences in the incidence of IVH and mortality. One of the trials included in the review has showed increased risk of PVL [75]. Based on these data, the authors have concluded that HFJ ventilation could not be supported as a primary mode of ventilation in premature infant.

Many centers use HFV as a rescue therapy for acute pulmonary dysfunction in the setting of failing conventional ventilation. At this time very little data is available to support that practice. There is only one clinical trial that specifically addresses this issue comparing HFOV and conventional ventilation [76] and although it has showed decrease in frequency of air leak in HFOV arm, at the same time there has been an increased rate of IVH. In a similar fashion, a single trial has compared rescue use HFJV with conventional ventilation [81] and showed increased treatment success in HFJV; however, this trial was conducted in the pre-surfactant era. Rescue HFV has been a subject of two Cochrane reviews $[82,83]$, which highlighted limited data availability and the need for further studies.

It is important to understand that nearly all clinical trials comparing HFV to conventional ventilation have been using pressure limited modes of ventilation. None of the trials above have compared HFV to volume-targeted ventilation.

\section{Strategies to Reduce Length of Invasive Mechanical Ventilation}

Despite our best efforts to avoid mechanical ventilation there is always going to be a group of premature infants that require invasive mechanical ventilation. Therefore, it is important to discuss strategies to reduce the length of mechanical ventilation. These strategies can be divided into three groups.

- Ventilator management (including choice of mode of ventilation, permissive hypercapnia and reduction of $\mathrm{O}_{2}$ exposure)

- Early extubation and prevention of re-intubation.

- Support measures including use of medications, medical gases and nutrition strategies.

Review of nutritional practices, use of medications such as postnatal steroids, diuretics and caffeine or medical gases such as nitric oxide or Heliox are beyond the scope of this review. Our goal is to review practices directly or indirectly associated with ventilator management.

Preference of ventilation modes has been the subject of many studies, yet the data to support one mode over another is limited. The best trial was by Reyes et al. [84], who compared the use of SIMV and SIMV with PS as a weaning mode of ventilation for premature infants with birth weight 500-1000 gm. It showed that the use of pressure support with SIMV resulted in earlier extubation and reduced oxygen dependency. Unfortunately the study failed to demonstrate reduction in total duration of mechanical ventilation or oxygen dependency, or oxygen need at 36 weeks gestational age alone or combined with death.

Several trials and meta-analysis demonstrated that volume-targeted ventilation resulted in overall reduction in length of mechanical ventilation, compared with pressure-targeted ventilation $[59,60,85]$ Direct comparison of volume- vs. pressure-targeted ventilation as an weaning strategy has been studied to address only short term effects and were small or inconclusive $[86,87]$.

Synchronized ventilation is associated with reduction of length of ventilation in premature infants, and its utility in the ventilation of premature infants has been adopted in most NICUs.

Permissive hypercapnea, acceptance of higher levels of $\mathrm{pCO}_{2}$ to reduce time and amount of ventilator support is now widely used yet the data to support this practice remains uncertain. Frequently cited trials of permissive hypercapnea, used it to prevent initial intubation and mechanical ventilation, rather than limit length of mechanical ventilation $[14,15,88]$. They reinforce the view that intubation should be avoided and/or delayed, if possible, with potential benefits of reduction of BPD and lung injury. Two randomized trials have compared the use of permissive hypercapnea in mechanically ventilated infants and demonstrated reduction in length of mechanical ventilation and no significant side effects $[89,90]$. There was no difference in the rate of BPD. Another trial [91] used permissive hypercapnea( $\mathrm{pC}_{2}$, 55-65 $\mathrm{mmHg}$ ) in the first seven days of life to reduce amount of mechanical ventilation in premature infants, but was discontinued early due to higher mortality and higher incidence of neuro developmental impairment in permissive hypercapnea arm. All these trials described above have looked at the use of permissive hypercapnea in immediate period after birth in premature infant with data suggesting that it should be used with caution at best. There have not been trials addressing the use of permissive hypercapnea in premature infants mechanically ventilated for prolonged periods of time for established BPD.

Limiting supplemental oxygen to achieve desired saturation can be used as another approach. Data available on effects of different targeted saturation levels on long-term outcomes and rates of retinopathy of prematurity [92-95]. These trials include pulmonary outcomes within different saturation groups. The BOOST trial showed that the higher oxygen saturation target increased the risk of adverse pulmonary events including pneumonia and/or exacerbations of chronic lung disease and the need for oxygen, diuretics, and re-hospitalization [93]. The SUPPORT trial [94] showed that the duration of oxygen supplementation was shorter in the lower oxygen-saturation group, although there were no difference in duration of mechanical ventilation. While lower saturation targets and decreased oxygen use is an attractive, too low a saturation target may increase mortality [96].

Successful extubation in a timely fashion as well as avoidance of re-intubation is an important component for reduction of the duration of mechanical ventilation. Well-defined criteria for extubation have become standard of care in many ICUs [97]. Several attempts have been made to develop similar criteria for neonates. Use of pulmonary mechanics to determine readiness for extubation [98] identifies neonates succeeding or failing extubation, but lacks validation of a prospective study. In a single center Randomized Controlled Trial (RCT), the Minute Ventilation Test was shown to reliably predicted the babies who have been ready for extubation earlier than clinical judgment alone [99]. This was a small study and showed a high need for re-intubation within 24 hours. Several studies have used a Spontaneous Breathing Test (SBT) in comparison to the historical control [100102]. Again, successful extubation occurred earlier than using clinical 
judgment alone. Kamlin et al has also used it for prospective validation within their center [102]. A recent prospective study combined both MVT and SBT and was highly predictive of failure to extubate [103].

Post-extubation management is critical for prevention of reintubation and could be used as a tactic to reduce the length of invasive mechanical ventilation and has become common practice. Cochrane review [104] initially published in 2003 and updated in 2007 identified nine eligible trials. They concluded that the use of nasal CPAP as respiratory support following extubation reduced the incidence of apnea, respiratory acidosis and increased oxygen requirements resulting in the decreased need for additional ventilatory support. Current data support that NIPPV reduces the rate of intubation in initial management of respiratory distress in premature infants [105] and has been reviewed in the this issue. The advantage of NIPPV over CPAP as a mode of respiratory support post-extubation is less clear. Several small clinical trials compared CPAP and NIPPV over a decade ago [106-108] and showed a lower incidence of re-intubation compared with the CPAP group. A more recent single center randomized trial has failed to show differences in the rate of reintubation between CPAP and NIPPV groups [109] with similar complications. The NIPPV group in this trial appeared to have higher risk factors and potentially acuity of the disease despite randomization. Although potential benefits and low complication risks of NIPPV support its use in immediate postextubation period, more studies are needed.

\section{Summary}

Over the last three decades our view on mechanical ventilation of premature infants has changed significantly. Despite the rising interest and attention to non-invasive modes of ventilation, patients with the highest risk for poor pulmonary outcomes still require invasive ventilation. Synchronized- and patient-triggered ventilation has become a standard of care in premature infants. It remains unclear if one way of triggering of breath is superior to another. With the new emerging technologies such as NAVA high quality clinical trials are essential to address the advantages of one mode of breath triggering over the other. Existing data support the use of volume-targeted modes of ventilation over pressure-limited in premature infants. Despite these data, current surveys outside of the US fail to show that volumetargeted ventilation has become the main mode of ventilation in the NICUs. Well-designed survey study addressing the question why it is not used more widely would be very helpful. High frequency ventilation still remains a viable option to conventional ventilation. Although it is not superior to pressure-limited ventilation as a primary mode, the data support that it can be used safely. Lack of trials comparing HFV to volume-targeted ventilation makes the choice even more complicated. Multiple techniques exist to shorten the length of invasive mechanical ventilation. Use of synchronized ventilation, volume-targeted ventilation and post-extubation CPAP results in shortening length of ventilation and prevention of re-intubation. Although permissive hypercapnea and targeting lower oxygen saturation could be beneficial for reduction of ventilation length and improving pulmonary outcomes they should be used with caution due to concern of long-term neuro developmental complications.

\section{References}

1. Fanaroff AA, Stoll BJ, Wright LL, Carlo WA, Ehrenkranz RA, et al. (2007) Trends in neonatal morbidity and mortality for very low birthweight infants. Am J ObstetGynecol 196: 147.

2. Lemons JA, Bauer CR, Oh W, Korones SB, Papile LA, et al. (2001) Very low birth weight outcomes of the National Institute of Child health and human development neonatal research network, January 1995 through December
1996. NICHD Neonatal Research Network. Pediatrics 107: E1.

3. Singh GK, Yu SM (1995) Infant mortality in the United States: trends, differentials, and projections, 1950 through 2010. Am J Public Health 85: 957964.

4. Mathews TJ, Miniño AM, Osterman MJ, Strobino DM, Guyer B (2011) Annual summary of vital statistics: 2008. Pediatrics 127: 146-157.

5. Murdock Al, Linsao L, Reid MM, Sutton MD, Tilak KS, et al. (1970) Mechanical ventilation in the respiratory distress syndrome: a controlled trial. Arch Dis Child 45: 624-633.

6. Northway WH Jr, Rosan RC, Porter DY (1967) Pulmonary disease following respirator therapy of hyaline-membrane disease. Bronchopulmonary dysplasia. N Engl J Med 276: 357-368.

7. Gregory GA, Kitterman JA, Phibbs RH, Tooley WH, Hamilton WK (1971) Treatment of the idiopathic respiratory-distress syndrome with continuous positive airway pressure. N Engl J Med 284: 1333-1340.

8. DeLemos RA, McLaughlin GW, Robison EJ, Schulz J, Kirby RR (1973) Continuous positive airway pressure as an adjunct to mechanical ventilation in the newborn with respiratory distress syndrome. AnesthAnalg 52: 328-332.

9. deLemos RA, Kirby RR (1980) Early development: intermittent mandatory ventilation in neonatal respiratory support. IntAnesthesiolClin 18: 39-51.

10. Marchak BE, Thompson WK, Duffty P, Miyaki T, Bryan MH, et al. (1981) Treatment of RDS by high-frequency oscillatory ventilation: a preliminary report. J Pediatr 99: 287-292.

11. Froese AB, Butler PO, Fletcher WA, Byford LJ (1987) High-frequency oscillatory ventilation in premature infants with respiratory failure: a preliminary report AnesthAnalg 66: 814-824.

12. Avery ME, Tooley WH, Keller JB, Hurd SS, Bryan MH, et al. (1987) Is chronic lung disease in low birth weight infants preventable? A survey of eight centers. Pediatrics 79: 26-30.

13. Van Marter LJ, Allred EN, Pagano M, Sanocka U, Parad R, et al. (2000) Do clinical markers of barotrauma and oxygen toxicity explain interhospital variation in rates of chronic lung disease? The Neonatology Committee for the Developmental Network. Pediatrics 105: 1194-1201.

14. SUPPORT Study Group of the Eunice Kennedy Shriver NICHD Neonata Research Network, Finer NN, Carlo WA, Walsh MC, Rich W, et al. (2010) Early CPAP versus surfactant in extremely preterm infants. N Engl J Med 362: $1970-$ 1979.

15. Morley CJ, Davis PG, Doyle LW, Brion LP, Hascoet JM, et al. (2008) Nasa CPAP or intubation at birth for very preterm infants. N Engl J Med 358: 700-708.

16. Ramanathan R, Sekar KC, Rasmussen M, Bhatia J, Soll RF (2012) Nasa intermittent positive pressure ventilation after surfactant treatment for respiratory distress syndrome in preterm infants <30 weeks' gestation: a randomized, controlled trial. J Perinatol 32: 336-343.

17. Meneses J, Bhandari V, Alves JG, Herrmann D (2011) Noninvasive ventilation for respiratory distress syndrome: a randomized controlled trial. Pediatrics 127 : 300-307.

18. Stoll BJ, Hansen NI, Bell EF, Shankaran S, Laptook AR, et al. (2010) Neonatal outcomes of extremely preterm infants from the NICHD Neonatal Research Network. Pediatrics 126: 443-456.

19. Rivera R, Tibballs J (1992) Complications of endotracheal intubation and mechanical ventilation in infants and children. Crit Care Med 20: 193-199.

20. Weiss M, Dullenkopf A, Fischer JE, Keller C, Gerber AC; European Paediatric Endotracheal Intubation Study Group (2009) Prospective randomized controlled multi-centre trial of cuffed or uncuffed endotracheal tubes in small children. Br J Anaesth 103: 867-873.

21. Klingenberg C, Wheeler KI, Owen LS, Kaaresen PI, Davis PG (2011) An international survey of volume-targeted neonatal ventilation. Arch Dis Child Fetal Neonatal Ed 96: F146-F148.

22. Sharma A, Greenough A (2007) Survey of neonatal respiratory support strategies. ActaPaediatr 96: 1115-1117.

23. Chatburn RL (2007) Classification of ventilator modes: update and proposal for implementation. Respir Care 52: 301-323.

24. Chatburn RL, Volsko TA, Hazy J, Harris LN, Sanders S (2012) Determining the basis for a taxonomy of mechanical ventilation. Respir Care 57: 514-524. 
Citation: Roumiantsev S (2013) Invasive Mechanical Ventilation in Premature Infants: Where do we Stand Today? J Pulmon Resp Med S13: 002. doi:10.4172/2161-105X.S13-002

25. Keszler M (2009) State of the art in conventional mechanical ventilation. J Perinatol 29: 262-275.

26. Cleary JP, Bernstein G, Mannino FL, Heldt GP (1995) Improved oxygenation during synchronized intermittent mandatory ventilation in neonates with respiratory distress syndrome: a randomized, crossover study. J Pediatr 126 407-411.

27. Jarreau PH, Moriette G, Mussat P, Mariette C, Mohanna A, et al. (1996) Patient-triggered ventilation decreases the work of breathing in neonates. Am J RespirCrit Care Med 153: 1176-1181.

28. Hummler H, Gerhardt T, Gonzalez A, Claure N, Everett R, et al. (1996) Influence of different methods of synchronized mechanical ventilation on ventilation, gas exchange, patient effort, and blood pressure fluctuations in premature neonates. PediatrPulmonol 22: 305-313.

29. Greenough A, Milner AD, Dimitriou G (2004) Synchronized mechanical ventilation for respiratory support in newborn infants. Cochrane Database SystRev : CD000456.

30. Greenough A, Dimitriou G, Prendergast M, Milner AD (2008) Synchronized mechanical ventilation for respiratory support in newborn infants. Cochrane Database SystRev : CD000456.

31. Dimitriou G, Greenough A, Laubscher B, Yamaguchi N (1998) Comparison of airway pressure-triggered and airflow-triggered ventilation in very immature infants. ActaPaediatr 87: 1256-1260.

32. Dimitriou G, Greenough A, Cherian S (2001) Comparison of airway pressure and airflow triggering systems using a single type of neonatal ventilator ActaPaediatr 90: 445-447.

33. Nassabeh-Montazami S, Abubakar KM, Keszler M (2009) The impact of instrumental dead-space in volume-targeted ventilation of the extremely low birth weight (ELBW) infant. PediatrPulmonol 44: 128-133.

34. Heulitt MJ, Thurman TL, Holt SJ, Jo CH, Simpson P (2009) Reliability of displayed tidal volume in infants and children during dual-controlled ventilation. PediatrCrit Care Med 10: 661-667

35. Verbrugghe W, Jorens PG (2011) Neurally adjusted ventilatory assist: a ventilation tool or a ventilation toy? Respir Care 56: 327-335.

36. Stein H, Firestone K, Rimensberger PC (2012) Synchronized mechanical ventilation using electrical activity of the diaphragm in neonates. ClinPerinatol 39: 525-542.

37. Alander M, Peltoniemi O, Pokka T, Kontiokari T (2012) Comparison of pressure-, flow-, and NAVA-triggering in pediatric and neonatal ventilatory care. PediatrPulmonol 47: 76-83.

38. Clement KC, Thurman TL, Holt SJ, Heulitt MJ (2011) Neurally triggered breaths reduce trigger delay and improve ventilator response times in ventilated infants with bronchiolitis. Intensive Care Med 37: 1826-1832.

39. Stein H, Howard D (2012) Neurally adjusted ventilatoryassist in neonates weighing <1500 grams: a retrospective analysis. J Pediatr 160: 786-789

40. Liet JM, Dejode JM, Joram N, Gaillard-Le Roux B, Bétrémieux P, et al. (2011) Respiratory support by neurally adjusted ventilatory assist (NAVA) in severe RSV-related bronchiolitis: a case series report. BMC Pediatr 11: 92.

41. Bordessoule A, Emeriaud G, Morneau S, Jouvet P, Beck J (2012) Neurally adjusted ventilatory assist improves patientâ€"ventilator interaction in infants as compared with conventional ventilation. Pediatr Res 72: 194-202.

42. Beck J, Reilly M, Grasselli G, Mirabella L, Slutsky AS, et al. (2009) Patientventilator interaction during neurally adjusted ventilatory assist in low birth weight infants. Pediatr Res 65: 663-668.

43. Ålander M, Peltoniemi O, Saarela T, Anttila E, Pokka T, et al. (2013) Current trends in paediatric and neonatal ventilatory care -- a nationwide survey. ActaPaediatr 102: 123-128.

44. Abubakar KM, Keszler M (2001) Patient-ventilator interactions in new modes of patient-triggered ventilation. PediatrPulmonol 32: 71-75.

45. Migliori C, Cavazza A, Motta M, Chirico G (2003) Effect on respiratory function of pressure support ventilation versus synchronised intermittent mandatory ventilation in preterm infants. PediatrPulmonol 35: 364-367.

46. Schulzke SM, Pillow J, Ewald B, Patole SK (2010) Flow-cycled versus timecycled synchronized ventilation for neonates. Cochrane Database SystRev: CD008246.
77. De Luca D, Conti G, Piastra M, Paolillo PM (2009) Flow-cycled versus timecycled SIPPV in preterm babies with RDS: a breath-to-breath randomised cross-over trial. Arch Dis Child Fetal Neonatal Ed 94: F397-F401.

48. Kapasi M, Fujino Y, Kirmse M, Catlin EA, Kacmarek RM (2001) Effort and work of breathing in neonates during assisted patient-triggered ventilation. PediatrCrit Care Med 2: 9-16.

49. Björklund LJ, Ingimarsson J, Curstedt T, John J, Robertson B, et al. (1997) Manual ventilation with a few large breaths at birth compromises the therapeutic effect of subsequent surfactant replacement in immature lambs. Pediatr Res 42: $348-355$

50. Dreyfuss D, Saumon G (1993) Role of tidal volume, FRC, and end-inspiratory volume in the development of pulmonary edema following mechanical ventilation. Am Rev Respir Dis 148: 1194-1203.

51. Hernandez LA, Peevy KJ, Moise AA, Parker JC (1989) Chest wall restriction limits high airway pressure-induced lung injury in young rabbits. J ApplPhysio 66: 2364-2368.

52. Kaiser JR, Gauss CH, Pont MM, Williams DK (2006) Hypercapnia during the first 3 days of life is associated with severe intraventricular hemorrhage in very low birth weight infants. J Perinatol 26: 279-285.

53. Fabres J, Carlo WA, Phillips V, Howard G, Ambalavanan N (2007) Both extremes of arterial carbon dioxide pressure and the magnitude of fluctuations in arterial carbon dioxide pressure are associated with severe intraventricular hemorrhage in preterm infants. Pediatrics 119: 299-305.

54. D'Angio CT, Chess PR, Kovacs SJ, Sinkin RA, Phelps DL, et al. (2005) Pressure-regulated volume control ventilation vs synchronized intermitten mandatory ventilation for very low-birth-weight infants: a randomized controlled trial. Arch PediatrAdolesc Med 159: 868-875.

55. Singh J, Sinha SK, Alsop E, Gupta S, Mishra A, et al. (2009) Long term followup of very low birthweight infants from a neonatal volume versus pressure mechanical ventilation trial. Arch Dis Child Fetal Neonatal Ed 94: F360-F362.

56. Lista G, Colnaghi M, Castoldi F, Condò V, Reali R, et al. (2004) Impact of targeted-volume ventilation on lung inflammatory response in preterm infants with respiratory distress syndrome (RDS). PediatrPulmonol 37: 510-514.

57. Cheema IU, Sinha AK, Kempley ST, Ahluwalia JS (2007) Impact of volume guarantee ventilation on arterial carbon dioxide tension in newborn infants: a randomised controlled trial. Early Hum Dev 83: 183-189.

58. Piotrowski A, Sobala W, KawczyÅ,ski P (1997) Patient-initiated, pressureregulated, volume-controlled ventilation compared with intermittent mandatory ventilation in neonates: a prospective, randomised study. Intensive Care Med 23: $975-981$.

59. Wheeler K, Klingenberg C, McCallion N, Morley CJ, Davis PG (2010) Volumetargeted versus pressure-limited ventilation in the neonate. Cochrane Database Syst Rev 11:CD003666.

60. Wheeler KI, Klingenberg C, Morley CJ, Davis PG (2011) Volume-targeted versus pressure-limited ventilation for preterm infants: a systematic review and meta-analysis. Neonatology 100: 219-227.

61. vanKaam AH, Rimensberger PC, Borensztajn D, De Jaegere AP; Neoven Study Group (2010) Ventilation practices in the neonatal intensive care unit: a cross-sectional study. J Pediatr 157: 767-771.

62. Lunkenheimer PP, Rafflenbeul W, Keller H, Frank I, Dickhut HH, et al. (1972) Application of transtracheal pressure oscillations as a modification of "diffusing respiration". Br J Anaesth 44: 627.

63. Sjöstrand U (1977) Summary of experimental and clinical features of highfrequency positive-pressure ventilation--HEPPV. ActaAnaesthesiolScandSupp 64: $165-178$

64. Frantz ID 3rd, Werthammer J, Stark AR (1983) High-frequency ventilation in premature infants with lung disease: adequate gas exchange at low tracheal pressure. Pediatrics 71: 483-488.

65. Pokora T, Bing D, Mammel M, Boros S (1983) Neonatal high-frequency jet ventilation. Pediatrics 72: 27-32.

66. Boros SJ, Mammel MC, Coleman JM, Horcher P, Gordon MJ, et al. (1989) Comparison of high-frequency oscillatory ventilation and high-frequency je ventilation in cats with normal lungs. PediatrPulmonol 7: 35-41.

67. Bell RE, Kuehl TJ, Coalson JJ, Ackerman NB Jr, Null DM Jr, et al. (1984) Highfrequency ventilation compared to conventional positive-pressure ventilation in the treatment of hyaline membrane disease in primates. Crit Care Med 12 764-768. 
Citation: Roumiantsev S (2013) Invasive Mechanical Ventilation in Premature Infants: Where do we Stand Today? J Pulmon Resp Med S13: 002. doi:10.4172/2161-105X.S13-002

Page 7 of 8

68. Thompson WK, Marchak BE, Froese AB, Bryan AC: High-frequency oscillation compared with standard ventilation in pulmonary injury model. J ApplPhysiol 52: 543-548.

69. Courtney SE, Durand DJ, Asselin JM, Hudak ML, Aschner JL, et al. (2002) Highfrequency oscillatory ventilation versus conventional mechanical ventilation for very-low-birth-weight infants. N Engl J Med 347: 643-652.

70. Carlo WA, Siner B, Chatburn RL, Robertson S, Martin RJ (1990) Early randomized intervention with high-frequency jet ventilation in respiratory distress syndrome. J Pediatr 117: 765-770.

71. Plavka R, Kopecký P, Sebron V, Svihovec P, Zlatohlávková B, et al. (1999) A prospective randomized comparison of conventional mechanical ventilation and very early high frequency oscillatory ventilation in extremely premature newborns with respiratory distress syndrome. Intensive Care Med 25: 68-75.

72. Gerstmann DR, Minton SD, Stoddard RA, Meredith KS, Monaco F, et al (1996): The Provo multicenter early high-frequency oscillatory ventilation trial: improved pulmonary and clinical outcome in respiratory distress syndrome. Pediatrics 98:1044-1057.

73. Ogawa Y, Miyasaka K, Kawano T, Imura S, Inukai K, et al. (1993) A multicenter randomized trial of high frequency oscillatory ventilation as compared with conventional mechanical ventilation in preterm infants with respiratory failure. Early Hum Dev 32: 1-10.

74. Van Reempts P, Borstlap C, Laroche S, Van der Auwera JC (2003) Early use of high frequency ventilation in the premature neonate. Eur J Pediatr 162: 219226.

75. Wiswell TE, Graziani LJ, Kornhauser MS, Cullen J, Merton DA, et al. (1996) High-frequency jet ventilation in the early management of respiratory distress syndrome is associated with a greater risk for adverse outcomes. Pediatrics 98: 1035-1043.

76. [No authors listed] (1989) High-frequency oscillatory ventilation compared with conventional mechanical ventilation in the treatment of respiratory failure in preterm infants. The HIFI Study Group. N Engl J Med 320: 88-93.

77. Thome U, Kössel H, Lipowsky G, Porz F, Fürste HO, et al. (1999) Randomized comparison of high-frequency ventilation with high-rate intermittent positive pressure ventilation in preterm infants with respiratory failure. J Pediatr 135: 39-46.

78. Cools F, Henderson-Smart DJ, Offringa M, Askie LM (2009) Elective high frequency oscillatory ventilation versus conventional ventilation for acute pulmonary dysfunction in preterm infants. Cochrane Database Syst Rev3:CD000104.

79. Cools F, Askie LM, Offringa M, Asselin JM, Calvert SA, et al. (2010) Elective high-frequency oscillatory versus conventional ventilation in preterm infants: a systematic review and meta-analysis of individual patients' data. Lancet 375 : 2082-2091.

80. Bhuta T, Henderson-Smart DJ (2000) Elective high frequency jet ventilation versus conventional ventilation for respiratory distress syndrome in preterm infants. Cochrane Database Syst Rev : CD000328.

81. Keszler M, Donn SM, Bucciarelli RL, Alverson DC, Hart M, et al. (1991) Multicenter controlled trial comparing high-frequency jet ventilation and conventional mechanical ventilation in newborn infants with pulmonary interstitial emphysema. J Pediatr 119: 85-93.

82. Joshi VH, Bhuta T (2006) Rescue high frequency jet ventilation versus conventional ventilation for severe pulmonary dysfunction in preterm infants. Cochrane Database Syst Rev : CD000437.

83. Bhuta T, Henderson-Smart DJ (2000) Rescue high frequency oscillatory ventilation versus conventional ventilation for pulmonary dysfunction in preterm infants. Cochrane Database Syst Rev : CD000438.

84. Reyes ZC, Claure N, Tauscher MK, D'Ugard C, Vanbuskirk S, et al. (2006) Randomized, controlled trial comparing synchronized intermittent mandatory ventilation and synchronized intermittent mandatory ventilation plus pressure support in preterm infants. Pediatrics 118: 1409-1417.

85. Sinha SK, Donn SM, Gavey J, McCarty M (1997) Randomised trial of volume controlled versus time cycled, pressure limited ventilation in preterm infants with respiratory distress syndrome. Arch Dis Child Fetal Neonatal Ed 77: F202-F205.

86. Scopesi F, Calevo MG, Rolfe P, Arioni C, Traggiai C, et al. (2007) Volume targeted ventilation (volume guarantee) in the weaning phase of premature newborn infants. PediatrPulmonol 42: 864-870.
87. Abd El-Moneim ES, Fuerste HO, Krueger M, Elmagd AA, Brandis M, et al. (2005) Pressure support ventilation combined with volume guarantee versus synchronized intermittent mandatory ventilation: a pilot crossover trial in premature infants in their weaning phase. PediatrCrit Care Med 6: 286-292.

88. Dunn MS, Kaempf J, de Klerk A, de Klerk R, Reilly M, et al. (2011) Randomized trial comparing 3 approaches to the initial respiratory management of preterm neonates. Pediatrics 128: e1069-e1076.

89. Carlo WA, Stark AR, Wright LL, Tyson JE, Papile LA, et al. (2002) Minima ventilation to prevent bronchopulmonary dysplasia in extremely-low-birthweight infants. J Pediatr 141: 370-374.

90. Mariani G, Cifuentes J, Carlo WA (1999) Randomized trial of permissive hypercapnia in preterm infants. Pediatrics 104: 1082-1088.

91. Thome UH, Carroll W, Wu TJ, Johnson RB, Roane C, et al. (2006) Outcome of extremely preterm infants randomized at birth to different $\mathrm{PaCO} 2$ targets during the first seven days of life. Biol Neonate 90: 218-225.

92. [No authors listed] (2000) Supplemental Therapeutic Oxygen for Prethreshold Retinopathy Of Prematurity (STOP-ROP), a randomized, controlled trial. I: primary outcomes. Pediatrics 105: 295-310.

93. Askie LM, Henderson-Smart DJ, Irwig L, Simpson JM (2003) Oxygen-saturation targets and outcomes in extremely preterm infants. N Engl J Med 349: 959-967.

94. SUPPORT Study Group of the Eunice Kennedy Shriver NICHD Neonatal Research Network, Carlo WA, Finer NN, Walsh MC, Rich W, et al. (2010) Target ranges of oxygen saturation in extremely preterm infants. N Engl J Med 362: 1959-1969.

95. Stenson B, Brocklehurst P, Tarnow-Mordi W; UK. BOOST II trial; Australian BOOST II trial; New Zealand BOOST II trial. (2011) Increased 36-week survival with high oxygen saturation target in extremely preterm infants. N Engl J Med 364: 1680-1682.

96. Askie LM, Brocklehurst P, Darlow BA, Finer N, Schmidt B, et al. (2011) NeOProM: Neonatal Oxygenation Prospective Meta-analysis Collaboration study protocol. BMC Pediatr 11: 6.

97. Epstein SK (2009) Weaning from ventilatory support. CurrOpinCrit Care 15 36-43.

98. Szymankiewicz M, Vidyasagar D, Gadzinowski J (2005) Predictors of successful extubation of preterm low-birth-weight infants with respiratory distress syndrome. PediatrCrit Care Med 6: 44-49.

99. Gillespie LM, White SD, Sinha SK, Donn SM (2003) Usefulness of the minute ventilation test in predicting successful extubation in newborn infants: a randomized controlled trial. J Perinatol 23: 205-207.

100. Vento G, Tortorolo L, Zecca E, Rosano A, Matassa PG, et al. (2004 Spontaneous minute ventilation is a predictor of extubation failure in extremelylow-birth-weight infants. J Matern Fetal Neonatal Med 15: 147-154.

101. Kamlin CO, Davis PG, Argus B, Mills B, Morley CJ (2008) A trial of spontaneous breathing to determine the readiness for extubation in very low birth weight infants: a prospective evaluation. Arch Dis Child Fetal Neonatal Ed 93: F305-F306.

102. Kamlin CO, Davis PG, Morley CJ (2006) Predicting successful extubation of very low birthweight infants. Arch Dis Child Fetal Neonatal Ed 91: F180-F183.

103. Kaczmarek J, Kamlin CO, Morley CJ, Davis PG, Sant'anna GM (2012) Variability of respiratory parameters and extubation readiness in ventilated neonates. Arch Dis Child Fetal Neonatal Ed.

104.Davis PG, Henderson-Smart DJ (2002) Nasal continuous positive airways pressure immediately after extubation for preventing morbidity in preterm infants. Cochrane Database Syst Rev 3: CD000143.

105. Bhandari $V(2012)$ Noninvasive respiratory support in the preterm infant. ClinPerinatol 39: 497-511.

106. Khalaf MN, Brodsky N, Hurley J, Bhandari V (2001) A prospective randomized controlled trial comparing synchronized nasal intermittent positive pressure ventilation versus nasal continuous positive airway pressure as modes of extubation. Pediatrics 108: 13-17.

107. Friedlich P, Lecart C, Posen R, Ramicone E, Chan L, et al (1999) A randomized trial of nasopharyngeal-synchronized intermittent mandatory ventilation versus nasopharyngeal continuous positive airway pressure in very low birth weight infants after extubation. J Perinatol 19: 413-418. 
Citation: Roumiantsev S (2013) Invasive Mechanical Ventilation in Premature Infants: Where do we Stand Today? J Pulmon Resp Med S13: 002. doi:10.4172/2161-105X.S13-002

108. Barrington KJ, Bull D, Finer NN (2001) Randomized trial of nasal synchronized intermittent mandatory ventilation compared with continuous positive airway pressure after extubation of very low birth weight infants. Pediatrics 107: 638-641.
109. Khorana M, Paradeevisut H, Sangtawesin V, Kanjanapatanakul W, Chotigeat $U$, et al (2008) A randomized trial of non-synchronized Nasopharyngeal Intermittent Mandatory Ventilation (nsNIMV) vs. Nasal Continuous Positive Airway Pressure (NCPAP) in the prevention of extubation failure in pre-term < 1,500 grams. J Med Assoc Thai 91 Suppl 3: S136-S142. 